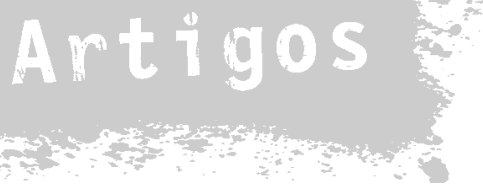

\section{Índios Missionários: Cultos Protestantes Entre os Xicrin do Bacajá ${ }^{1}$}

Clarice Cohn Os Xikrin nunca tiveram a experiência da evangelização: nunca conviveram

Para Aracy Lopes da Silva, em homenagem ao carinho e à generosidade com que

sempre

se dedicou à formação de novosantropólogos.

Campos 1:9-30, 2001. com missionários protestantes em sua aldeia. No entanto, atualmente eles têm aderido a uma prática protestante, que inclui cultos nos fins-de-semana no espaço interno da aldeia, e a formação de jovens pastores no que denominam "cursos", junto a missionários, mas no exterior da aldeia, em um sítio em São Félix do Xingu. Não se constituindo numa "imposição" externa, esse movimento de conversão tem que ser entendido a partir de suas motivações ao estabelecer essa nova modalidade de relações internas e externas, práticas rituais e visão de mundo. Para isso, deve-se buscar na prática religiosa, nas relações que ela estabelece e nas expectativas voltadas à conversão uma compreensão desse movimento, que é de fato uma segunda tentativa de internalização de um ethos crente, e que, portanto, tem em si um caráter flutuante. Esse texto busca entender o que está por trás dela, sem recorrer a uma abordagem de perdas ou de coerção; ao contrário, mesmo que não se possa saber qual vai ser seu lugar no futuro desse povo, já que a instituição de uma prática crente é recente, tenta sugerir modos de compreender o que os leva a se dirigir a uma relação com os missionários e com o cosmos por eles pregados.

Tendo-se em vista tal objetivo, o texto foi estruturado em duas partes. $\mathrm{Na}$ primeira, é apresentado um histórico da entrada do protestantismo a partir das informações disponíveis para outros grupos Kayapó, e daquelas originadas em minhas pesquisas em campo na aldeia xikrin do Bacajá ${ }^{2}$, em uma introdução à análise da prática protestante dos Xikrin do Bacajá. Essa é abordada em sua espacialidade, enfocando a interiorização da religião e dos cultos, realizados no 
centro da aldeia; em sua temporalidade, em que se marca um corte no cotidiano pelos cultos nos fins-de-semana; e em sua replicação de uma divisão sociológica pré-existente, a oposição de jovens e velhos. Para tanto, é apresentada uma reflexão comparativa com as informações disponíveis sobre outros sub-grupos kayapó e voltada às transformações realizadas a partir de um modelo de vida social que subsiste.

Em uma segunda parte, busco lançar uma possibilidade de compreensão das motivações dos Xikrin para aderir ao protestantismo, analisando sua escatologia e sugerindo que a mensagem da vida eterna surge como uma possibilidade de solucionar um mal-estar cosmológico, o da dificuldade de separação dos vivos e dos mortos. Essa reflexão é inserida em um debate atual na etnologia brasileira sobre as conversões indígenas à religião protestante vistas a partir de sua própria perspectiva.

\section{OS XIKRIN DO BACAJ Á E A PRÁTICA PROTESTANTE}

\section{A entrada do protestantismo no Bacajá}

Os Xikrin do Bacajá são um sub-grupo Kayapó estabelecido no sudoeste do Pará. Sendo o grupo Kayapó que vive mais ao Norte, eles contam com uma história longa de distanciamento do contato e procura de novas terras, sendo considerados os que menos foram afetados pelas influências da sociedade envolvente dentre esses grupos. O antropólogo William Fisher (1991) calcula a chegada dos Xikrin à região do rio Bacajá como tendo ocorrido em 1926 ou 27, e data o primeiro contato oficial dos Xikrin do Bacajá com os brancos em 1959, quando um grupo do SPI os encontrou perto da foz do Igarapé Golosa, tendo como conseqüência uma forte epidemia e a fuga dos índios. Em 1961, ocorre um outro contato, dessa vez no Igarapé Carapanã. Algum tempo depois, os Xikrin se estabelecem junto ao posto do SPI chamado de Francisco Meirelles abaixo do Igarapé Dois Irmãos. Em 1965, mudam-se para o local onde hoje habitam. Durante todo esse período, mantêm contatos, às vezes belicosos, com a aldeia xikrin do Cateté (cf. Vidal 1977 e Fisher 1991).

A atuação dos missionários protestantes entre os Kayapó remonta à época do contato, quando a Unevangelized Fields Mission (UFM), ou, mais precisamente, seu braço brasileiro, a Missão de Evangelização Mundial, se estabelece entre os Gorotire em fins da década de 1930, 
dando assistência à saúde, atividade que havia sido negligenciada pelo SPI, também estabelecido na aldeia (Inglez de Sousa no prelo; Turner 1993a). Inglez de Sousa cita algumas indicações fornecidas pelos Kayapó de Gorotire de que o missionário que trabalhava nessa aldeia na época, Horance Banner, teria iniciado um esforço de alfabetização, e relata a história que se segue. $\mathrm{Na}$ década de 1960, a UFM, conhecida então como Miceb (Missão Cristã Evangélica do Brasil), passa a manter escolas, alfabetizando principalmente em kayapó, mas também, em alguns casos, em português. Em meados da década seguinte, a Funai estabelece uma escola na aldeia, contratando duas professoras que se dedicavam às aulas em português, mas também duas missionárias, que permaneciam alfabetizando em kayapó. Esse arranjo parece permanecer até a década de 1980, quando o maior envolvimento com as atividades econômicas de garimpo e extração de madeira resulta em uma grande evasão escolar. Na década seguinte, com a educação indígena passando para o Ministério da Educação, os missionários continuam a alfabetizar em kayapó, embora se tornem menos atuantes, e se voltam mais claramente à leitura do Novo Testamento (Inglez de Sousa no prelo). Turner (1993a) acredita que a atuação evangelizadora tenha perdido força entre os Gorotire, e que atualmente sua conversão é menos provável.

O Novo Testamento é traduzido para o kayapó por outra missão protestante, o SIL (Summer Institute of Linguistics, ou Sociedade Internacional de Lingüística), e, de acordo com Silva \& Salanova (no prelo), a grafia estabelecida por esses missionários é dada a conhecer aos Kayapó em 1974, desde então sofrendo apenas algumas alterações quando os próprios missionários acreditam que elas facilitarão a leitura para os Kayapó. Esses autores, que tratam de outro sub-grupo Kayapó, os Mekranoti, afirmam que o SIL atua em suas aldeias desde 1972, tendo grande envolvimento na alfabetização na língua indígena voltada à doutrinação. Os autores reportam ainda que todas as aldeias mekranoti têm pastores índios, que são levados para encontros semestrais em São Félix do Xingu.

No Bacajá, a religião protestante chegou com um jovem proveniente da aldeia xikrin do Cateté, lá convertido e alfabetizado. Deixando uma jovem esposa e filhos pequenos na aldeia de origem, esse jovem se estabelece no Bacajá, criando laços de parentesco e se casando novamente. A partir de relatos da época de sua chegada, fica-se sabendo que esse jovem, Bep-komati, tentou organizar cultos semanais, os quais tiveram aparente aceitação mas já tinham sido abandonados em 1993, época de minha primeira visita. Desde então, por vários anos, os únicos a entoarem alguns cânticos, em casa, eram Bep-komati e outro jovem, que os havia aprendido quando morava em outra aldeia kayapó. Bep-komati, porém, mantinha seu Novo Testamento, e o lia solitariamente quando podia. 
Assim, o protestantismo, tolerado na intimidade, tinha sido como que silenciado na aldeia.

Ele ganha nova vida quando, por volta de 1997, os Xikrin recebem no Bacajá visitas de um missionário. Os relatos dessas visitas indicam que o visitante era o próprio Trapp, missionário do Miceb com décadas de experiência entre os Kayapó, e que causa grande impressão entre os Xikrin por ser, como me diziam, um velho de cabelos brancos que fala muito bem a língua deles e entende muito de sua cultura. Essas visitas dão início a uma nova fase, na qual quatro jovens de sexo masculino começam a passar algumas temporadas no que chamam de "curso" em um sítio mantido no município próximo à aldeia de São Félix do Xingu (o que, portanto, indicaria uma atuação conjunta do SIL com a Miceb). Nesses cursos, são alfabetizados e aprendem o Novo Testamento e a parafernália ritual dos cultos. Em paralelo a essas visitas, os Xikrin recebem fitas gravadas com cânticos traduzidos para sua língua (em uma tradução, aliás, que eles declaram gostar muito, e que apreciam esteticamente).

Desde então, certamente desde 1998, esses jovens realizam cultos semanais (aos fins-desemana) no centro da aldeia, espaço ocupado cotidianamente para as reuniões masculinas.

\section{A entrada do material protestante: fitas com cânticos e o Novo Testamento}

Em uma sociedade de tradição oral, as fitas gravadas com cânticos são bem recebidas, e podiam ser ouvidas em quase todas as casas em 1998. Sabe-se que os Kayapó têm tido, assim como outros povos indígenas, uma estratégia de "domesticação" da tecnologia de registro de fatos e acontecimentos ${ }^{3}$. Os Xikrin planejam dominar a técnica de gravação em vídeo, e se utilizam freqüentemente dos gravadores para registrar rituais realizados na aldeia ou de que participam ou observam em aldeias que visitam, trocando inclusive fitas com outros grupos étnicos, valorizando assim o aprendizado de cantos e melodias (quando a letra lhes é incompreensível) de outros povos. Sua apropriação de rituais de outros povos tampouco é novidade, e exemplos disso são o Kuoro Kangô, de origem juruna, e o Bô, esse último o Aruanã dos Karajá, rituais freqüentemente realizados e valorizados. Os Xikrin enfatizam a necessidade de uma perpetuação, pela transmissão, de seu kukradjà, o que poderíamos glosar como "tradição cultural" (Cohn 2000:125-127; Fisher 1991:313-315; Lea 1986:64-65), mas que deve ser entendido, como procurei demonstrar (Cohn idem), para além de um conjunto de traços que conformam um todo, como o que lhes dá especificidade étnica, traços diacríticos voltados à produção da identidade xikrin, e que é um 
conjunto aberto, sempre passível de novas inclusões e remanejamento. Assim, a própria transmissão não é vista por eles como uma reprodução estática de um repertório, mas como algo que possibilita a mudança e a renovação.

A atividade guerreira kayapó volta-se a essa produção contínua de kukradjà e esteve sempre associada a raptos de mulheres e crianças, que Ihes ensinaram, ao longo da história, canções, algumas até hoje entoadas, quando as pessoas, ocasionalmente, lembram sua origem a partir de outras etnias, e algumas tendo adquirido conotações rituais, sendo incorporadas no ciclo ritual ${ }^{4}$. Principalmente, os Xikrin gostam muito de cantar. Assim, como as fitas trazidas de rituais testemunhados em outras terras, os cânticos protestantes foram rapidamente aprendidos por várias pessoas, especialmente as mais jovens e as crianças.

O Novo Testamento, porém, teve uma entrada mais restrita, já que se limitava aos quatro jovens alfabetizados para esse fim. Por isso mesmo, talvez, tenha ganhado um valor adicional, e esses jovens se orgulham de sua capacidade de lê-lo. A valorização do Novo Testamento liga-se portanto à valorização da palavra escrita e da alfabetização, espaço que a educação formal leiga não conseguiu ocupar em uma longa história de fracassos.

No Bacajá, a educação formal tem décadas de história, mas de um modo tão intermitente que não há, hoje, sequer uma geração alfabetizada. Assim, se muitos, inclusive homens que hoje têm 40 anos, lembram ter freqüentado aulas, há atualmente na aldeia apenas seis pessoas que, em maior ou menor grau, sabem ler. Quem melhor domina a escrita em português é um homem de origem Gavião que foi criado fora de sua aldeia natal e adotado pelos Xikrin do Bacajá quando adolescente, lá tendo casado e se fixado como um importante intermediário entre os Xikrin e os regionais ou a Funai. Bep-komati conta como um dos homens alfabetizados, tendo, por seu turno, domínio da escrita em kayapó na grafia do SIL. Um terceiro homem nasceu na aldeia do Bacajá, mas viveu alguns anos na aldeia xikrin do Cateté, onde freqüentou a escola e aprendeu a ler, embora com alguma dificuldade. Os outros três são os jovens que se uniram a Bep-komati nos "cursos" em São Félix do Xingu, e estão em pleno processo de alfabetização.

Assim, a história recente do grupo, com a figura de Manoel Gavião, provou ser a escrita um meio privilegiado de capacitação para intermediar com os regionais e os órgãos oficiais e ganhar papel de destaque na política do grupo (Manoel foi adotado por um dos chefes, a quem chama de pai, e, auxiliando-o no contato com os "brancos", tem sempre acesso a bens industrializados). Por outro lado, a escola, aos olhos dos Xikrin, não se mostrou capaz de suprir a demanda de 
"conhecimento do mundo dos brancos" que mantinham. Vê-se, portanto, que tanto a habilidade de ler que pode ser explicitada nos cultos quanto os "cursos" realizados pelos missionários são valorizados pelos Xikrin, o que pode ser visto pela adesão entusiasta dos jovens escolhidos.

No entanto, a história do envolvimento das missões com a educação indígena nos leva a questionar essa eficácia que os Xikrin atribuem a seus "cursos"s. Silva e Salanova (no prelo) demonstram que a grafia formulada pelo SIL é apresentada aos Kayapó-Mekranoti como correspondendo exatamente à fala, e não como uma convenção lingüística, tendo como conseqüência o fato de que, embora sintam dificuldades na utilização dessa grafia, os Kayapó não conseguem discuti-la e buscar uma solução para ela. Assim, a alfabetização não é estabelecida em diálogo com os índios, mas apresentada, autoritariamente, como tendo um modelo único.

Mais grave, porém, seja talvez o fato de que, como demonstram Silva e Salanova (idem), alfabetizando para converter, os missionários não criam uma educação que auxilie realmente os índios a compreender o que tanto anseiam, esse mundo em que vivem aqueles com quem são obrigados a dialogar e negociar, ou seja, a sociedade nacional para além dos, ou não restrita aos, evangélicos. Os autores sugerem mesmo que alguns Kayapó leriam o Novo Testamento tentando encontrar nele indicações para entender o modo de vida contemporâneo dos "brancos". O trabalho educativo dos missionários entre os Mekranoti volta-se ao modelo de bilinguismo de transição, relegando à escola leiga formal o ensino do português e de qualquer conteúdo referente aos conhecimentos da sociedade envolvente, esse a ser realizado em português. Assim, os missionários protestantes se retiram de qualquer compromisso com uma formação dos Kayapó que seja voltada à sua relação com a sociedade envolvente, restringindo-se portanto à capacitação para a leitura do Novo Testamento. Essa ênfase é demonstrada ainda por outra observação de Silva e Salanova, a de que os missionários se esforçam para formar bons leitores (desnecessário dizer, da Bíblia), dedicando-se pouco às atividades de escrita, restringindo portanto a alfabetização a apenas um de seus aspectos e limitando a capacidade de obter o domínio da comunicação escrita por aqueles que são assim alfabetizados.

\section{Os cultos}

Atualmente, os cultos são realizados nos fins-de-semana, estando a cargo dos quatro jovens pastores. A definição do domingo como dia santo é anterior ao advento da regularização dos

14 cultos, e origina-se dos muitos contatos que os Xikrin mantêm com regionais; para eles, o domingo 
é dito pi-ôk kamrek, escrita vermelha, já que vem marcado nessa cor na maior parte dos calendários. Embora muito difundida, essa definição não é em muitos casos posta em prática pelos Xikrin, que freqüentemente desconsideram o costume de não trabalhar no domingo e seguem para as roças e para a caça e pesca. Alguns já há tempos se preocupam, porém, em saber em que dia da semana estão, para resolver se vão ou não trabalhar, afirmando que é perigoso trabalhar aos domingos porque, no caso de sofrer um acidente, custa-se a sarar. Os jovens, por sua vez, definiram o sábado e o domingo como dias dedicados aos jogos de futebol. Eles sabem em que dia da semana estão perguntando aos funcionários do Posto Indígena (ou à antropóloga), pelo rádio comercial, ou, quando a escola está funcionando, pelo descanso semanal dos professores. Assim como os fins-de-semana, os feriados são também acompanhados com atenção, e o natal e o fimde-ano são comemorados com danças no pátio e forró. Ressalte-se, porém, que o conhecimento sobre a prática de não trabalhar em fins-de-semana e feriados é bastante difundido, mas ela nem sempre é seguida. Às vezes, isso é uma questão privada (se se vai trabalhar ou não); às vezes, conta com a decisão da coletividade (no caso de festas). O futebol e os cultos protestantes, portanto, dão novo sentido aos fins-de-semana, que passam a se estabelecer de fato como um dia diferenciado e um corte no cotidiano.

Os cultos acontecem no centro da aldeia de formato circular, no ngà, edifício central utilizado cotidianamente pelos homens para suas reuniões no entardecer e à noite, nas quais se dedicam a discutir a política interna da aldeia, sua relação com o exterior, e a cantar e contar histórias e mitos. Esse é um espaço privilegiadamente masculino, descrito na literatura sobre os povos jê como constituindo o "domínio público", onde acontece a política aldeã, e que tem um importante papel na reunião de gerações de homens, com relações, de parentesco ou afinidade, diversas entre si, e, embora longe de exclusivo, no aprendizado de saberes culturais (cf. Cohn 2000). Ele é assim o espaço da coletividade dos homens, no qual o acesso das mulheres é restrito. Mas as mulheres ocupam também esse espaço nos momentos de preparativos de um ritual.

Os rituais Xikrin são masculinos ou femininos, no sentido de voltados para cada um dos gêneros, ou seja, não limitando a participação a um dos sexos, mas definindo a participação do outro sexo como subordinada, como coadjuvante. Antes dos rituais, há um período de "ensaios", em que as músicas que lhes dão a seqüência de eventos são repetidas. Esse momento é realizado pelos homens reunidos no ngà, enquanto as mulheres se reúnem em um círculo entre o centro e a casa da esposa do chefe para ensaiar. No entanto, quando todos estão se adornando para o ritual, 
algumas partes dessa ornamentação, a colagem da penugem de periquito no corpo e de ovo de azulão no rosto, são realizadas, para homens e para mulheres, no interior do ngà. Como a penugem de periquito é aplicada pelos amigos formais, que podem ser de ambos os sexos, acontece novamente a reunião dos dois sexos no interior do ngà, mas ainda em uma relação subordinativa. O ovo de azulão, por sua vez, é manipulado apenas por homens, e são eles, portanto, a aplicá-lo nas mulheres quando estas realizam um ritual - mas nelas e para elas. Assim, os preparativos de um ritual são momentos em que os dois sexos podem se reunir no ngá, mas mantendo entre si uma relação subordinativa - não se trata de reclusão ou isolamento (o ngà, exceto no caso do ritual Bô, em que mulheres e crianças não podem ver a confecção das máscaras, não é fechado por paredes, e todos geralmente podem ver e ouvir o que lá acontece), mas do uso desse espaço por e para um dos sexos.

Nos cultos protestantes, porém, o ngà é ocupado por ambos os sexos, em relação de igualdade e com o mesmo objetivo. Nessas ocasiões, os homens se reúnem no exterior do prédio central, em um círculo no pátio forrado com palha de buriti, a qual, coletada diariamente, simboliza a reunião dos homens, e tentam dar continuidade às suas reuniões cotidianas, esforçando-se por ignorar as atividades protestantes. Vê-se, assim, que os cultos não foram censurados pela coletividade, mas que deles nem todos participam, nem todos tendo aderido à nova religião.

Quem participa dos cultos são principalmente os jovens - jovens solteiros (das categorias de idade meprintire e menoronyre, respectivamente moças e rapazes em idade de casar mas ainda solteiros) e jovens casais com filhos pequenos ou esperando seu primeiro filho. Qual a razão dessa adesão dos jovens e da tolerância ${ }^{6}$ mas desconsideração dos mais velhos? Uma explicação possível é a própria divisão da sociedade xikrin em categorias de idade, que às vezes se expressa em um antagonismo e às vezes estabelece uma relação de complementaridade", a existência de "chefes de categoria de idade", os "chefes novos", ou seja, jovens que, alinhados politicamente com um dos dois chefes da aldeia, se responsabilizam pelas atividades coletivas de sua categoria de idade ${ }^{8}$, e as próprias atividades coletivas segmentadas pelas categorias de idade. Assim, jovens casais se reúnem na casa de seu chefe de categoria, e as mulheres assim alinhadas se pintam coletivamente, opondose ao grupo das mulheres mais velhas, que se pintam, também coletivamente, com um motivo diferente (Vidal 1992). Os jovens já tinham dado sinais de uma tentativa de "autonomização" frente aos mais velhos, quando, em 1995, tentaram viabilizar uma roça coletiva, que, no entanto, embora iniciada, não teve continuidade, diz-se que por ter sido o terreno mal-escolhido e muito longe. 
pelos mais velhos, que às vezes o olham com desconfiança e às vezes se mostram simpáticos à prática crente, que prega o bom costume - não beber, não fumar e não cometer adultério. 0 consumo de bebidas alcóolicas é hábito recente, já que os Kayapó nunca a produziram, e não têm estabelecido momentos para seu consumo, como acontece em outros grupos, e é tido como desestabilizador. Já o caso do tabaco é interessante: os Xikrin dizem que o fumo era associado ao amadurecimento e envelhecimento e à prática xamânica, sendo o tabaco utilizado apenas pelos velhos e xamãs, e que só recentemente, com o contato, todos, homens e mulheres, jovens e velhos, fumam; a proibição de fumar reverteria novamente essa situação, já que os "crentes" são jovens. A proibição do adultério, porém, deve ser abordada com maior cuidado. Os Xikrin mantêm uma prática de troca ritual de casais, o aben pa amu, pelo qual se estabelece não só a possibilidade de haver relações sexuais entre os diversos cônjuges envolvidos, resultando no fato de que eles chamam de "filhos" aqueles oriundos de ambos os casamentos, mas também à reciprocidade alimentar; eles enfatizam que, quando um dos homens se ausenta, o outro deve se responsabilizar pelo fornecimento de caça e pesca à esposa deste; de mesmo modo, as mulheres de responsabilizam pelo fornecimento de produtos da roça e da floresta em caso de ausência de uma delas. Há ainda evidências de "amantes" de homens, que não foram formalizadas pelo reconhecimento público do aben pa $a m u^{9}$, com quem sua esposa mantém reciprocidade em trocas alimentares. No entanto, há casos de adultério que são tidos como ilícitos, e que podem levar a conflitos entre mulheres ${ }^{10}$. São a esses que os Xikrin se referem quando afirmam que o modus vivendi crente vem a pacificar as relações, e jamais transportam essa proibição para as trocas institucionalizadas e reconhecidas mais ou menos publicamente.

Mais freqüentemente, porém, as gerações mais velhas parecem apostar em um modismo da juventude, que eles toleram até que o entusiasmo esfrie. Eles não deixam, principalmente, de ter um discurso "tradicionalista", e de lembrar, como sempre o fizeram, em falas formais ou corriqueiras, os jovens da necessidade de manterem sua cultura, e seguirem sendo Xikrin ${ }^{11}$. Portanto, os homens mais velhos têm negociado o lugar que os cultos e a crença protestante irão ocupar em sua "tradição cultural" tal como a definimos acima, não afirmando taxativamente a sua incorporação em curso como um abandono de sua especificidade, mas, simultaneamente, a relembrando aos jovens; essa atitude me parece coerente com a prática de incorporação de novos modos de expressão ritual, mas de modo que se apresente em benefício da manutenção dessa identidade diferenciada.

Para a maior parte dos jovens que aderiram à religião protestante, não se coloca um dilema 
ou uma irredutibilidade entre os mitos e saberes xikrin e a pregação e a cosmovisão protestante. Assim, é como se para muitos os dois modos de ver o mundo e estabelecer relações com ele possam andar em paralelo, não suscitando incompatibilidades ou conflitos. Quanto à vida cotidiana, os "crentes" não se diferenciam dos demais, inclusive no sinal mais externo de não abdicar do hábito de fumar. No entanto, em pelo menos um caso, o de um dos jovens pastores, a evangelização, embora recente, levou a uma recusa dos mitos e à afirmação de que eles eram fantasiosos, que são histórias que os velhos contam mas que não aconteceram. Expressado por apenas um desses jovens, porém, essa parece ser uma (não)solução individual; e deve-se lembrar sempre da possibilidade de ser a evangelização, pelo menos em seu sentido mais coletivo, um fenômeno passageiro, repetindo-se assim a experiência anterior (embora, ao contrário do que acontece agora, sem apoio e individual) de instituição do culto protestante por Bep-komati.

Os cultos são, portanto, realizados nos finais de semana no espaço central, político-ritual, do ngà, ocupado cotidianamente pelos homens e ritualmente por cada um dos sexos que realiza um ritual. Neles, reúnem-se moças e rapazes, solteiros ou recém casados. Os cultos são conduzidos pelos jovens pastores, que se alternam na leitura de trechos do Novo Testamento, quando são ouvidos pelos jovens em silêncio e de cabeça baixa (atitude que a etiqueta xikrin define como respeitosa); entre os trechos, ele entoam cânticos, momento em que são acompanhados pelos jovens presentes, e nos quais se percebe o pleno domínio que têm do repertório musical utilizado nesses cultos. Assim, embora os missionários estejam presentes indiretamente na formação e evangelização dos jovens pastores, que se dá no exterior da aldeia, em outras terras, a prática protestante não tem mediação de um missionário, sendo realizada no interior da aldeia (e não em uma igreja construída em suas imediações) e pelos próprios Xikrin, o que demonstra ao mesmo tempo sua adesão, tácita ou ativa, e a força centrípeta que ela ganha, prática exógena cujo fator de exterioridade é negado pela mediação distante e pouco visível de estrangeiros.

\section{COSMOVISÕES: A MORTE E A VIDA ETERNA}

Já foi dito que os jovens "crentes" não percebem, em geral, o evangelho e seus ensinamentos como incompatíveis e conflitantes com os saberes e a cosmologia dos Xikrin, havendo uma única exceção conhecida. Foi dito também que os mais velhos, embora não tenham aderido aos cultos e deles não 
participem, mantêm uma dupla atitude de tolerância e indiferença, embora continuem (ou seja, como sempre) a exortar os jovens a respeitar sua cultura e a manter sua identidade xikrin - mas que isso nem sempre se coloca em termos de perdas culturais, já que sua própria concepção de 'tradição cultural" admite reformulações. Falta-nos ainda saber quais seriam as motivações, para além do fator sociológico possível do antagonismo, ou no mínimo diferenciação, entre as categorias de idade, dessa adesão. Para isso, devemos ouvi-las dos próprios Xikrin.

O que os jovens que se mantêm atentos às possibilidades de inovação fornecidas pelo protestantismo nos dizem é que quem não se converte ao protestantismo está fadado a sofrer depois da morte, e depois de morrer sentirá muita dor. Como devemos entender essa afirmação como uma tradução cultural da ameaça de que os infiéis, aqueles que se recusam a se converter, vão arder no inferno, ou como uma busca de solução de algo que para eles não é solucionado em sua própria cultura, uma contradição que parece insolúvel, ou seja, o destino dos mortos? Sem poder descartar completamente a primeira hipótese, visto não ter sido realizada uma pesquisa sistemática sobre a conversão em si e os discursos evangelizadores, e sem deixar de lembrar o apelo mais "pragmático" da relação com os missionários e de seu domínio da escrita, mencionado acima, optamos por uma busca de uma explicação interna, a de recepção de um discurso que vem se encaixar em uma espécie de incômodo cultural, a da definição da natureza dos mortos e de seu destino. Para isso, precisamos percorrer a escatologia xikrin.

\section{A morte e o destino dos mortos}

Os Xikrin possuem um discurso relativamente pouco elaborado e estruturado sobre o sentido da morte, a natureza dos mortos e seu destino final, especialmente se comparados a outros grupos jê, como os Krahô (cf. Carneiro da Cunha 1978). Vidal já havia notado esse ponto, e cito suas palavras:

"Contrariamente ao que se verifica entre os Bororo e entre os Krahó a morte entre os Kayapó não é motivo de grandes ritos ou de elaboração conceitual mais abrangente e sendo assim não chegou a suscitar maior interesse por parte dos antropólogos... [Penso] que o estudo da morte não é um ângulo, uma abordagem privilegiada que nos permita entender melhor a sociedade kayapó como um todo" (1983:317).

Assim, de fato, a morte não é, ainda hoje, privilegiada pelos antropólogos em suas análises, e, embora haja indicações sobre ela em Turner (1967, anexo II), Giannini (1991), Vidal (1977), Lea 
(1986) e Cohn (2000), nunca ganhou o status de eixo analítico sobre o qual se elaboram e organizam interpretações e compreensões sobre os Kayapó.

A morte é, para os Xikrin, a separação irreparável de seu karon, glosado comumente como alma, duplo, de seu corpo - irreparável porque o karon pode se ausentar momentaneamente do corpo adormecido e vagar, possibilitando os sonhos, assim como a atividade xamânica. Não está claro o destino dos mortos, que, se são descritos como vagando solitariamente, são tratados no mito como um coletivo, como o demonstra o trabalho acima citado de Vidal, que recebe o novo morto e vive como os vivos em uma "aldeia dos mortos". Na realidade, como nota essa autora (1983:321), é o rompimento com o mundo dos vivos, e não o destino dos mortos, que é enfatizado nas concepções xikrin da morte; voltaremos a essa questão.

Depois de consumida pela terra a carne do corpo sepulto, restam os ossos, que eram tradicionalmente tratados e mantidos pelos parentes vivos, e o karon (além de, frisaria Lea [1986], os nomes, que são transmitidos entre gerações e garantem a reprodução da sociedade). Enquanto a carne não foi ainda consumida pela terra e o karon não se despregou ainda plenamente do corpo, o defunto é objeto de cuidados, sendo mantidos junto à cova não só seus objetos de uso cotidiano e ritual como água, para se ele tiver sede, e um fogo aceso ao entardecer, para que não sinta frio.

Quando o karon se desprega do corpo definitivamente, vai se encontrar com os outros mortos, que o recebem com um choro ritual e pedem notícias dos parentes vivos (Vidal 1983:321). Sua travessia é longa e, especialmente para as crianças, perigosa (e elas necessitam de um acompanhante, um parente adulto, que lhes mostre o caminho, e evite que ela seja comida pela onça; cf. Cohn 2000, Vidal:1983). Lá chegando, continuam o ciclo de vida e se casam, e as crianças, criadas por parentes mais velhos, crescem. Os mortos, no entanto, padecem de muitos dos males comuns aos vivos, especialmente a saudade, e essa é a razão para pedirem notícias dos vivos: saber quando se dará o reencontro. Assim, eles se aproximam da roça, espaço intermediário entre a aldeia e a floresta em que habitam, espécie de exterior domesticado (cf. Giannini 1991), para rever suas parentas vivas - e por isso elas cospem sempre que vão à roça, para não serem vulneráveis aos mekaron. Assim também, retornam à aldeia para assistir aos rituais realizados pelos vivos - e por isso os que assistem ao ritual abandonam as casas e acampam no pátio, deixando-as para ser ocupadas pelos mortos.

Os mortos estão, enfim, sempre à busca de se reaproximar dos vivos e de levá-los consigo. Os 20 Xikrin, portanto, temem a aproximação de um karon, e Vidal (1983:317) descreve um mito em que se 
conta a história de um xamã que tenta recuperar sua filha morta, combatendo para isso os mekaron, que dela não querem se separar. Em um caso de uma morte de uma criança que testemunhei, os trovões ouvidos durante a noite foram pressentidos como um sinal de que os mortos, simbolizados pelo trovão, viriam buscar "o filho de alguém" (me'õ nhõ kra), ou seja, uma criança, que dependeria de um parente mais velho para mostrar-lhe o caminho para se encontrar com os demais mortos.

Assim sendo, a grande dificuldade com que os Xikrin se defrontam com a morte é a da separação, do rompimento com o mundo dos vivos. Se os Krahô podem ver a morte como a superação da afinidade e das tensões dela resultante, e a passagem para um mundo de consanguíneos, mesmo que esse resulte estéril (Carneiro da Cunha 1978), os Xikrin, que têm, como nota Vidal (1983), a reunião masculina no centro da aldeia como um mediador e espaço de encontro para além da esfera da afinidade, não parecem enfatizar esse ponto. Pelo contrário, seu grande sofrimento advém da separação dos parentes que permanecem vivos, que tentam sempre levar para perto de si, e o estabelecimento de novas relações depois da morte não ameniza a saudade que sentem dos vivos e sua ligação com eles.

Se a ênfase da escatologia kayapó está na passagem do mundo dos vivos ao mundo dos mortos, já que "o que vem depois não interessa mais aos vivos e fica além de qualquer possibilidade de controle" (1983:321), é exatamente essa passagem, irreversível (como mostra a história do xamã que não consegue recuperar a filha) mas nunca um rompimento de fato, já que os mortos permanecem ligados aos vivos por laços de consangüinidade, e ansiando sempre pelo momento de reunião, que se mostra problemática.

\section{A MENSAGEM DA VIDA APÓS A MORTE}

Assim, a escatologia xikrin aponta para uma dificuldade em estabelecer definitivamente a passagem para o mundo dos mortos, em garantir o rompimento com os vivos. Os vivos estão portanto constante e eternamente ameaçados pelos mortos, que por sua vez estão condenados a padecer com a saudade dos que deixaram para trás; o laço não se rompe por completo.

Mas os Xikrin dizem que é necessária a conversão à religião protestante para que não se sofra após a morte. O Novo Testamento traduz para o kayapó a figura de Deus (ou J esus?) como Methindjwy, algo que poderíamos traduzir livremente como o senhor dos vivos. Por que a escolha dos missionários 
por essa tradução? Ou melhor, como ela é entendida pelos Xikrin? Não é irrelevante que o poder de Deus seja simbolizado pela esfera dos vivos ${ }^{12}$, e podemos pensar que a mensagem da vida eterna apareça para os Xikrin como uma solução para o que Ihes parece insolúvel, o rompimento dos mortos do mundo dos vivos. Portanto, poderíamos sugerir que a mensagem da vida após a morte ganhe um valor positivo para os Xikrin a partir de uma inversão - inversão porque, ganhando a vida eterna, eles se tornam não menos mortos, mas mais vivos, e capazes de ganhar finalmente autonomia frente aos que ficaram, os vivos, e romper sua ligação com eles. A promessa da vida eterna figura assim como uma solução definitiva para a situação ambígua dos mortos na concepção xikrin, definitivamente separados dos vivos mas a eles sempre ligados, pairando como uma ameaça.

\section{ALGUMAS CONSIDERAÇÕES FINAIS}

Esse texto deve ser entendido como uma análise preliminar por duas razões nada irrelevantes: a primeira é que não é fruto de um trabalho exaustivo de coleta de dados, a segunda, a pouca profundidade temporal e o caráter até hoje flutuante do fenômeno da evangelização dos Xikrin. No entanto, há algumas indicações que saltam aos olhos. Os Xikrin, na realidade, fazem uma segunda tentativa de introdução do protestantismo, tendo a primeira fracassado. O que irá acontecer, ou está acontecendo, com essa nova tentativa, não podemos adivinhar, e as alternativas são múltiplas: o protestantismo pode se expandir, continuar no domínio daqueles que já aderiram, os jovens, ou voltar à letargia. Mas sabemos que sua introdução não se deve a um poder coercitivo exterior, sendo, de algum modo, uma iniciativa interna, ligada à possibilidade de alfabetização e aquisição de novos papéis sociais que são possibilitados, mais que impostos, pelos missionários, que se mantêm, a maior parte do tempo, ausentes da aldeia.

Sabemos também que o "corte sociológico" que ele estabelece não é uma novidade, mas, ao contrário, já estava dado: as categorias de idade, e a oposição entre jovens e velhos, que poderia mesmo, como mostra a história kayapó tal como eles a contam, resultar em uma nova cisão da aldeia. Assim, tanto as motivações dos jovens quanto a relativa indiferença dos mais velhos são iluminadas por esse fator.

No entanto, estabelecer que há uma motivação cosmológica para aderir ao protestantismo não significa afirmar que os jovens xikrin se converteram. Na realidade, temos aqui uma situação 
em que os crentes não se revelam seja na vida cotidiana, estabelecendo novas sociabilidades ou costumes, seja em sua concepção sobre o mundo. Tudo indica que os jovens têm no discurso sobre a morte uma motivação para se incluir em um culto que os reúne e diferencia dos mais velhos, em uma nova roupagem para uma clivagem que the é anterior. $O$ fato de que esses mesmos jovens permanecem participando das atividades cotidianas e rituais, e mesmo ouvindo respeitosamente as exortações dos mais velhos, o corrobora.

Um "mal-estar" sociológico ou cosmológico foi descrito por análises antropológicas recentes da conversão como uma razão para a aceitação do protestantismo em regiões e grupos indígenas diversos. Assim, Vilaça (1996) sugere que os Wari' puderam, com a conversão, realizar em vida o que só poderiam realizar em morte, a consanguinização de sua sociedade, e Capiberibe (2000) mostra como a evangelização proporcionou uma quebra do sistema de agressões no qual se inclui a vingança e conforma uma sociedade crivada pela guerra e pela morte. Aqui, a promessa da vida eterna vem a romper com uma existência terrena de sofrimento, dor e tristeza, e faz com que laços não sejam rompidos. Para os Xikrin, pelo contrário, como vimos, ela permite realizar a separação dos mortos em relação aos vivos, livrando uns da saudade e da dor, e os outros do medo constante. Podemos ainda citar Andrello (1999:303), que demonstra que os Taurepáng reconheceram no cristianismo algo que não Ihes era dado por sua cosmologia, a existência de um "bom lugar" no plano terrestre, e que, localizado agora no céu, é interpretado em conjunto a uma série de inversões, que o transforma, e à figura de J esus, esse tornado o simétrico oposto do herói cultural Makunaima. O que não quer dizer que sempre encontraremos, nas histórias de conversões, encaixes perfeitos seja da sociologia seja da cosmologia indígena com o cristianismo pregado, como o demonstra a experiência dos Baniwa analisada por Wright, que

"desde o início ... detectaram defeitos na utopia [cristã tal como pregada], que levaram muitos a suspeitar que aquilo em que eles tinham entrado não era a sociedade que esperavam criar"(1999: 211).

Mas a história da conversão pode ser revertida, como aprenderam rapidamente os jesuítas (Viveiros de Castro 1992) e como foi o caso dos Wari'. Vilaça ressalta que a memória que eles guardam do tempo (recente) em que eram crentes é das melhores, mas que mesmo assim eles abandoaram o protestantismo: 
"Foram crentes e gostaram. Mas não puderam permanecer crentes por muito tempo, e devemos nos perguntar porquê. Talvez não tenham jamais deixado de gostar da vida de crente, justamente porque o que estava em jogo eram seus próprios pressupostos culturais, mas descoberto que determinados ideais não eram para ser vividos. Com o tempo, acabaram por confirmar o que a vida em sociedade já lhes havia ensinado há muito: que os afins são um mal necessário" (Vilaça 1996:129)

No Bacajá, o que irá acontecer só o tempo nos dirá. Tudo o que podemos fazer é tentar entender o que acontece hoje, e porque os jovens passaram a aderir ao protestantismo - a uma prática ritual protestante (ao culto), e mais duvidosamente a uma moralidade ou crença protestante. O que se sugere aqui é que esse fenômeno pode ser visto, e interpretado, em suas múltiplas dimensões - a espacialidade, o local do culto, a ocupação do centro da aldeia por homens e mulheres reunidos com um mesmo fim; a temporalidade, o caráter de divisão do cotidiano, instituindo o dia santo e o dia regular de culto; a divisão pelas categorias de idade, paralela a uma divisão que ocorre nas atividades cotidianas e na política, e nas atribuições frente à continuidade da "tradição"; e, por fim, a recepção de uma mensagem específica pregada pelo cristianismo, a da vida eterna, a qual surge para os Xikrin como uma solução para um dilema estrutural, a condição dos mortos e sua relação com os vivos. Assim, se para os Wari' houve um "encontro de sociologias" enquanto para os Tupinambá houve um "encontro de cosmologias" (Vilaça 1996:117), a atual adesão dos Xikrin ao protestantismo deve ser interpretada levando-se em conta sociologias e cosmologias.

Clarice Cohn émestre em Antropologia Social pela Universidade de São Paulo e pesquisadora do M ARI Grupo de Educação Indígena dessa mesma universidadee do Cedec - Centro deEstudosde Cultura Contemporânea. 


\section{NOTAS}

1 Esse artigo resulta de um paper apresentado no Fórum de Pesquisa F.14 - "Missões em áreas indígenas: fronteiras e traduções" na XXII Reunião Brasileira de Antropologia (Brasília, julho de 2000). Agradeço os comentários e sugestões dos participantes do Fórum (especialmente Marta Amoroso, Paula Montero e Antonella Tassinari), e o convite feito por Marta Amoroso, que me incentivou a refletir sobre esse tema. Essa reflexão foi tornada possível pelos financiamentos fomecidos pela FAPESP para as pesquisas em campo (por meio de auxílio pesquisa e do Projeto Temático "Antropologia, História, Educação", desenvolvido no MARI/USP, no período de 1993 a 1999, totalizando pouco mais de 8 meses), e pelo CNPq, que concedeu uma bolsa de mestrado, instituições a que agradeço. Foi também possibilitada pelas lições de antropologia dadas por minha orientadora, Lux Vidal, durante todo o trabalho de pesquisa. Por fim, agradeço aos pareceristas, que fizeram uma leitura cuidadosa desse texto, fornecendo valiosas sugestões.

2 Os Xikrin são um sub-grupo Kayapó, e se dividem em quatro aldeias estabelecidas em duas reservas: a do Cateté, na qual se encontram as aldeias do Cateté e Djudjiekô, e a do Trincheira-Bacajá, com duas aldeias, Bacajá e Trincheira, estabelecidas às margens do Rio Bacajá, um afluente do Xingu. Há outros sub-grupos Kayapó, distribuídos em diversas Terras Indígenas e aldeias, mas que se classificam em três grandes divisões, os Kayapó-Gorotire, os Kayapó-Mekrangoti e os Kararaô.

3 Cf. a análise do uso do vídeo pelos Gorotire em Turner (1993b).

4 Verswijver (1992) demonstra como os Mekrangoti tinham uma modalidade bélica, contra índios de outras etnias, que se destinava à aquisição de cantos, danças e ornamentos, e ao rapto de crianças e mulheres; Turner (1993a) demonstra como os Gorotire incorporam bens industrializados tomando-os nekretch, termo utilizado por esse subgrupo kayapó de mesmo modo que os Xikrin usam kukradjà.

5 Para uma análise da introdução de uma cultura letrada em sociedades orais pelo SIL e sua relação oficial com a educação indígena, veja Mendes Barros (1994).

6 Ressalte-se que a tolerância dos mais velhos do entusiasmo dos jovens pelo protestantismo não é aqui pensado como uma "tolerância religiosa" no sentido em que utilizamos esse termo, juridicamente, hoje, mas pretende indicar essa atitude de não censurar mas também se manter distante.

7 Cf. Verswijver (1992), Vidal (1977) e Turner (1992), em que se relata e analisa clivagens de aldeias baseadas em categorias de idade, e Turner (1967), em que o antagonismo entre as gerações é apresentado a partir dos jogos. Cf. também Vidal (1976), em que se discute as categorias de idade e Vidal 1977, em que a complemetaridade ritual das categorias de idade é analisada.

8 Cf, para isso, Vidal (1977), em que se documenta a origem histórica desse rearranjo político entre os Xikrin do Cateté, e Fisher (1991) e Cohn (2000) para os Xikrin do Bacajá.

9 Pelo qual as mulheres, enquanto os homens estão fora da aldeia para realizar a caçada coletiva que provê um ritual, escolhem e anunciam para a platéia constituída das mulheres e dos poucos homens que permaneceram na aldeia uma outra mulher com quem estabelecerá essa relação, o que será confirmado posteriormente pelos homens envolvidos, quando retornam com a caça, em uma fala pública para o coletivo dos homens.

10 É interessante notar que essa prática parece se basear na generosidade das mulheres, que escolhem seu par. Em um ritual que assisti, quando as mulheres definiam seu par, pude perceber que algumas utilizavam esse momento para reconhecer uma relação extra-conjugal do marido, escolhendo sua "amante" solteira para par, caso no qual evidentemente não se beneficiam da troca. Assim como, mais informalmente, reconhecem essas ligações pelo estabelecimento de trocas alimentares. Por outro lado, há casos de crianças geradas por encontros extra-conjugais de homens com mulheres solteiras que foram posteriormente adotadas pelo casal, a esposa tratando-o como filho, mas sem esconder sua origem biológica. Mas nem toda relação extra-conjugal dos homens tem um tal "final feliz", e pode gerar conflitos. 
11 Cf. Graham (1995) para uma análise do discurso de "seguir sempre sendo um Xavante" na performance ritual que tem origem em um sonho entre esse povo.

12 Me é o coletivizador; thin são os vivos, os que têm saúde; djwy é utilizado como sufixo para marcar alguém como possuidor de algo (seja objeto, conhecimento ou prerrogativas rituais) ou como detentor de uma qualidade (como no termo do chefe, benadwyry, aquele que faz a fala ritual que define e simboliza sua condição). 


\section{REFERÊNCIAS BIBLIOGRÁFICAS}

ANDRELLO, Geraldo. 1999. "Profetas e Pregadores: a conversão taurepáng à religião do Sétimo Dia”. In: Robin Wright (org.), Transformando os Deuses. Os múltiplos sentidos da conversão entre os povos indígenas no Brasil. Campinas: Editora da Unicamp.

CAPIBERIBE, Artionka M. 2000. Da vingança ao perdão: a presença da religião cristã entre os Palikur. Paper apresentado no Fórum de Pesquisa Missões em áreas indígenas: fronteiras e traduções, na XXII Reunião Brasileira de Antropologia.

CARNEIRO DA CUNHA, Manuela. 1978. Os mortos e ou outros. Uma análise do sistema funerário e da noção de pessoa entre os Krahó. São Paulo: Hucitec.

COHN, Clarice. 2000. A criança indígena: a concepção Xikrin de infância e aprendizado. Dissertação de Mestrado. Universidade de São Paulo.

FISHER, William H. 1991. Dualism and its Discontents: social organization and village fissioning among the Xikrin-Kayapo of Central Brazil. Ph.D. Dissertation. Faculty of the Graduate School of Cornell University.

GIANNINI, Isabelle Vidal. 1991. A Ave Resgatada: "A impossibilidade da Leveza do Ser". Dissertação de Mestrado. Universidade de São Paulo.

GRAHAM, L.R. 1995. Performing Dreams: discourses of immortality among the Xavante of Central Brazil. Austin: University of Texas Press.

INGLEZ DE SOUSA, Cássio Noronha (no prelo) - "Aprendendo a viver junto: reflexões sobre a experiência escolar kayapó-gorotire". In: Aracy Lopes da Silva \&Mariana K. L. Ferreira (org.), Antropologia, História e Educação. São Paulo: Global/MARI-USP/FAPESP.

LEA, Vanessa. 1986. Nomes e Nekrets Kayapó: uma concepção de riqueza. Tese de Doutorado. Museu Nacional/UFRJ .

MENDES BARROS, Maria Candida Drummond. 1994. "Educação bilíngüe, lingüística e missionários". Em aberto 4 (63), jul/set.

SILVA, Maria Amélia Reis \&SALANOVA, Andrés Pablo. no prelo. "A assessoria lingüística nos projetos escolares indígenas: o caso da formação de professores mebêngôkre". In: Aracy Lopes da Silva \& Mariana K. L. Ferreira (org.), Antropologia, História e Educação. São Paulo: Global/MARI-USP/FAPESP.

TURNER, Terence. 1966. Social structure and political organization among the Northern Kayapo. Ph.D. Dissertation. Cambridge, MA: Harvard University.

TURNER, Terence. 1992. “Os Mebengokre Kayapó: história e mudança social, de comunidades autônomas para a coexistência interétnica". In: Manuela Carneiro da Cunha (org.), História dos índios no Brasil. São Paulo: FAPESP/SMC/Companhia das Letras.

. 1993a. "De cosmologia a História: resistência, adaptação e consciência social entre os Kayapó". In: Eduardo Viveiros de Castro \&Manuela Carneiro da Cunha (org.), Amazônia: etnologia e história indígena. São Paulo: NHII-USP/FAPESP. 
. 1993b. "Imagens desafiantes: a apropriação kayapó do vídeo". Revista de Antropologia, 36.

VERSWIJ VER, Gustaf. 1992. The Club-Fighters of the Amazon. Warfare amog the Kayapo Indians of Central Brazil. Gent: Rijkuniversteit.

VIDAL, Lux. 1976. "As categorias de idade como sistema de classificação e controle demográfico de grupos entre os Xikrin do Cateté e de como são manipulados em diferentes contextos". In: Actes du XLIle Congrès International des Américanistes. Paris: Societé des Américanistes.

. 1977. Morte e Vida de uma Sociedade Indígena Brasileira. São Paulo: Hucitec.

. 1983. "A morte entre os índios Kayapó". In: J osé de Souza Martins (org.), A morte e os mortos na sociedade brasileira. São Paulo: Hucitec.

. 1992. "A Pintura Corporal e a Arte Gráfica entre os Kayapó-Xikrin do Cateté". In: Grafismo Indígena. São Paulo: Nobel/EDUSP/FAPESP.

VILAÇA, Aparecida. 1996. “Cristãos sem fé: alguns aspectos da conversão dos Wari' (Pakaa Nova)”. Mana, 2 (1): 109-137.

VIVEIROS DE CASTRO, Eduardo. 1992. "O mármore e a murta: sobre a inconstância da alma selvagem". Revista de Antropologia, 35: 21-74.

WRIGHT, Robin M. 1999. “O tempo de Sophie: história e cosmologia da conversão baniwa”. In: Robin Wright (org.), Transformando os Deuses. Os múltiplos sentidos da conversão entre os povos indígenas no Brasil. Campinas: Editora da Unicamp. 


\section{RESUMO}

Embora jamais tenham tido uma missão atuando em sua área, os Xikrin do Bacajá têm realizado cultos protestantes desde 1998. Essa situação, de uma prática missionária que não conta com a participação direta de pessoas estrangeiras ao grupo, as quais se limitam à formação de jovens pastores, oferece uma oportunidade privilegiada para refletir sobre seu estabelecimento e a adesão de um grupo indígena a ela. Realizando uma etnografia dos cultos, o artigo aborda sua temporalidade, espacialidade e os papéis sociais neles envolvidos, e conclui com uma reflexão sobre o modo e as razões pelas quais o grupo adere aos cultos e, talvez em menor grau, ao ethos "crente". Para isso, retoma as noções xikrin sobre a morte, estabelecendo um paralelo entre a vida após a morte do modo como os Xikrin a concebe e sua leitura do que é prometido pelo protestantismo.

\section{ABSTRACT}

Although they have never had a mission actuating in their area, the Xikrin from Bacajá have performed protestant cults since 1998. This missionary practice that does not have direct participation of people foreign to the group, which limits itself to the formation of young ministers. This is a situation which offers a privileged opportunity for a reflection on the establishment of a missionary practice and the adherence of an indigenous group. Offering an ethnography of the cults, the article focuses on their space and time organization and the social roles involved, concluding with a reflection on the ways and reasons for which the group adheres to the cults and, maybe to a lesser degree, to the "crente" ethos. In order to do that, it considers Xikrin notions of death, establishing a parallel between life after death according to Xikrin conceptions and their understanding of that which is promised by Protestantism. 